\title{
Fabrication Cycle Time and Shipment Decision for A Multiproduct Intra-Supply Chain System with External Source and Scrap
}

\author{
Yuan-Shyi Peter Chiu \\ Department of Industrial Engineering and Management, \\ Chaoyang University of Technology, Taichung 413, Taiwan. \\ E-mail: ypchiu@cyut.edu.tw \\ Jia-Hang Jhan \\ Department of Industrial Engineering and Management, \\ Chaoyang University of Technology, Taichung 413, Taiwan. \\ E-mail: k649014888@gmail.com \\ Victoria Chiu \\ Department of Accounting, Finance and Law, \\ State University of New York at Oswego, Oswego, NY 13126, USA. \\ E-mail: victoria.chiu@oswego.edu \\ Singa Wang Chiu \\ Department of Business Administration, \\ Chaoyang University of Technology, Taichung 413, Taiwan. \\ Corresponding author: swang@cyut.edu.tw
}

(Received December 23, 2019 ; Accepted April 9, 2020)

\begin{abstract}
Managers of today's transnational firms, facing competitive global business environments, always intend to optimize their intra-supply chain systems to meet customers' multiproduct demands with perfect quality goods, timely delivery, and minimum fabrication-shipping expenses. In the production units of intra-supply chain systems, random scraps are inevitable due to various unforeseen factors. Also, since the in-house capacity is limited, implementing a partial outsourcing plan can help release machine workloads, smooth production schedule, and reduce fabrication uptime. Inspired by these facts, this study explores an intra-supply chain system with random scraps and an external source. We build a mathematical model to portray the characteristics of the studied problem. Model analyses and the renewal reward theorem help us to obtain the expected system cost function. Optimization techniques and Hessian matrix equations are used to jointly decide the optimal cycle time and shipment policy that minimize the expected system cost. Through numerical illustration, we expose the individual and joint impact of diverse system features on the optimal operating policies and other crucial parameters of the studied problem, thus, facilitate managerial decision makings.
\end{abstract}

Keywords- Industrial engineering, Production management, Outsourcing, Scrap, Intra-supply chain system, Multiple shipments.

\section{Introduction}

The present study explores the manufacturing cycle length and shipment decision for a multiproduct intra-supply chain system with random scrap and external source. The intra-supply chain system exists in today's translational enterprises, in which product demand is fabricated in local production units and finished items are transported to the remote sales locations to meet customer's needs. 
International Journal of Mathematical, Engineering and Management Sciences

Vol. 5, No. 4, 614-630, 2020

https://doi.org/10.33889/IJMEMS.2020.5.4.050

Schwarz et al. (1985) examined a single-warehouse multi-retailer delivery system with the assumption that the fill-rate is relating to the safety stock of warehouses and retailers. The authors maximized fill-rate using a few known approximation models and came up with suggestions on characteristics of fill-rate strategy to facilitate managerial decision-making. Sarker and Khan (1999) optimized the optimal production batch size under the periodic distribution plan. Authors first constructed a cost function for their proposed system, then they presented a solution process to decide both the optimal raw materials ordering and manufacturing batch size policies to minimize total expenses for the system. Additional studies (Ashfaq et al., 2017; Batukhtin et al., 2019; Lin et al., 2019; Mosca et al., 2019) explored fabrication systems with diverse aspects of distribution features in (intra-)supply chain environments.

Unlike the simple assumption of the economic production quantity model (Taft, 1918), wherein the optimal batch size was derived under a perfect single-product fabrication process; today's producers facing competitive global markets must meet customer's increasing multiproduct demands with high product quality. Zahorik et al. (1984) studied a multi-stage multi-item limited capacity fabrication scheduling problem using network programming techniques. Two systems with linear relating costs were considered, a limited shipping capability and a bottleneck existence in the last process stage. The authors proposed a three-period rolling heuristic employing linear network programming to find the optimal solutions. Limitations of their heuristic were discussed and their results were compared to that found by the use of linear programming. Zipkin (1995) examined the performance of a multi-item fabrication system. Two different modes for information collection and utilization were considered, a first-come-first-served policy and a longest-queue policy, to derive the closed-form performance measurements. The author used simulation techniques to test and illustrate their findings and discussed some fundamental managerial issues. Other studies (Vujosevic et al., 2017; He et al., 2018; Chiu et al., 2019) explored different features of multiproduct manufacturing systems.

Due to the existence of unanticipated factors in real fabrication processes, the production of imperfect items is inevitable. Henig and Gerchak (1990) examined a production-inventory system under a periodic review and stochastic imperfect rate. Li et al. (2008) studied a repair and rework system at an automotive paint shop with random first-time quality. The authors presented a case study on the redesign of a repair and rework system to demonstrate that variations in first-time quality may lead to a reduction in the quality buy rate and an increase in unnecessary repaints, thus a waste of production capacity and materials. Additional studies (Khanna et al., 2017; Al-Bahkali and Abbas, 2018; Zhao et al., 2018) addressed different imperfect characteristics of production systems. Moreover, limited capacity is always a key issue in production planning, to adopt a partial outsourcing policy can be an effective alternative to meet customer order's due date. Levina and Ross (2003) examined the vendor's information technology (IT) outsourcing value proposition. The authors particularly focused on the perspective, including practices and strategies, from successful application management IT outsourcer. Their results specified vendor's efficiency was counted on economic benefits deriving from its capability of building up a fine set of core competencies from its past series of IT projects. The authors suggested how to assess the values of IT outsourcing according to their findings and existing knowledge on the client-vendor relationship. Arya et al. (2008) studied the strategic outsourcing policy to a common supplier in the presence of a rival. Instead of focusing on a conventional concept in cost savings (i.e., comparing unit outsourcing cost to unit in-house fabrication cost), authors pointed out that by outsourcing to the firm and its retail rival's common supplier, can limit the incentive the supplier offering favorable terms to its rival, thus may lower its rivals' ability to compete. Other studies (Chiu et al., 2017; 
International Journal of Mathematical, Engineering and Management Sciences

Vol. 5, No. 4, 614-630, 2020

https://doi.org/10.33889/IJMEMS.2020.5.4.050

Mohammadi, 2017; Skowronski et al., 2018; Hamers et al., 2019) explored production systems with diverse features of outsourcing plans. Since past studies paid little attention to the system considering the joint effects of multiproduct, outsourcing, and random scrap, the present study aims to fill the gap.

\section{Problem Description}

Fabrication cycle time and shipment decision for a multiproduct intra-supply chain system incorporating external source and random scrap are explored. Notation utilized in this study is provided in Appendix A. Consider an intra-supply chain system has a production unit which plans to fabricate $L$ different products on single equipment under a rotation cycle time discipline, at a rate $P_{1 i}$ to meet products' demand rate $\lambda_{i}$ (where $i=1,2, \ldots, L$ ). To shorten the required cycle length in the planning of batch production, a partial outsourcing plan is implemented. For each end product $i$ in any replenishment cycle, there is a $\pi_{i}$ portion of the batch quantity that is supplied by an external source. These outsourced items are quality guaranteed by the external supplier and are promised to be received after fabrication uptime of the other $\left(1-\pi_{i}\right)$ portion of the batch (see Figure 1). As a result of this partial outsourcing plan, separate fixed and unit outsourcing costs, $K_{\pi \mathrm{i}}$ and $C_{\pi \mathrm{i}}$, are included in the system cost analysis.

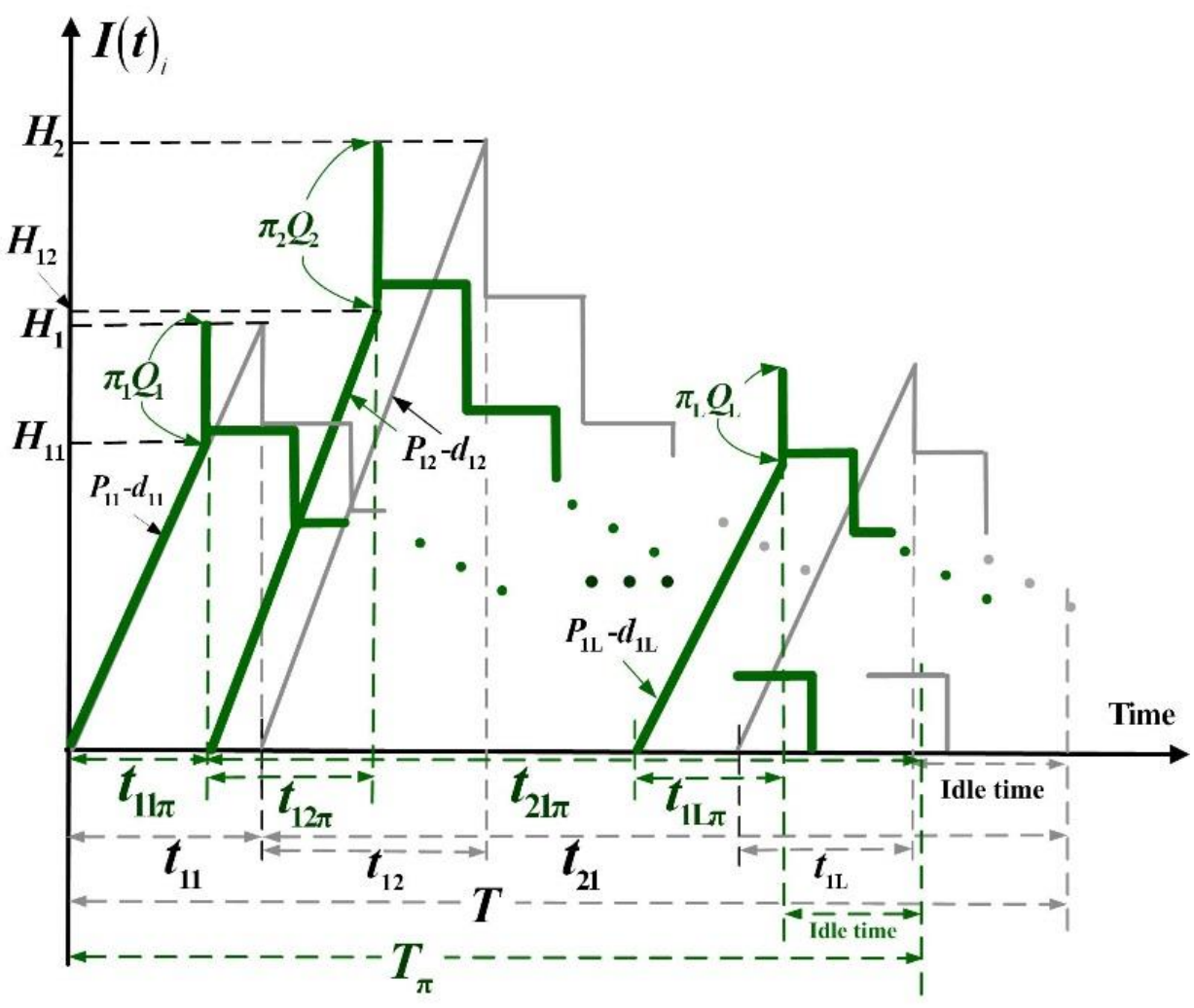

Figure 1. Inventory status of finished product $i$ in the proposed system incorporating external source and scrap 
In the production unit, due to different unforeseen factors in the manufacturing process, $x_{i}$ proportion of scraps are fabricated randomly at a rate $d_{1 i}$ (thus $d_{1 i}=x_{i} P_{1 i}$ ). Figure 2 exhibits the inventory status of scrapped items pf product $i$. The stock-out conditions are not permitted, therefore, $\left(P_{1 i}-d_{1 i}-\lambda_{i}\right)$ must greater than zero. Upon completion of fabrication of each product $i$, the outsourced items are received and the on-hand inventory level of finished item $i$ reaches $H_{i}$ at the end of uptime $t_{1 \text { iir. }}$. Then, fixed-amount $n$ installments of $H_{i}$ are shipped to sales units at fixed time interval $t_{\text {ni }}$ (refer to Figure 1).

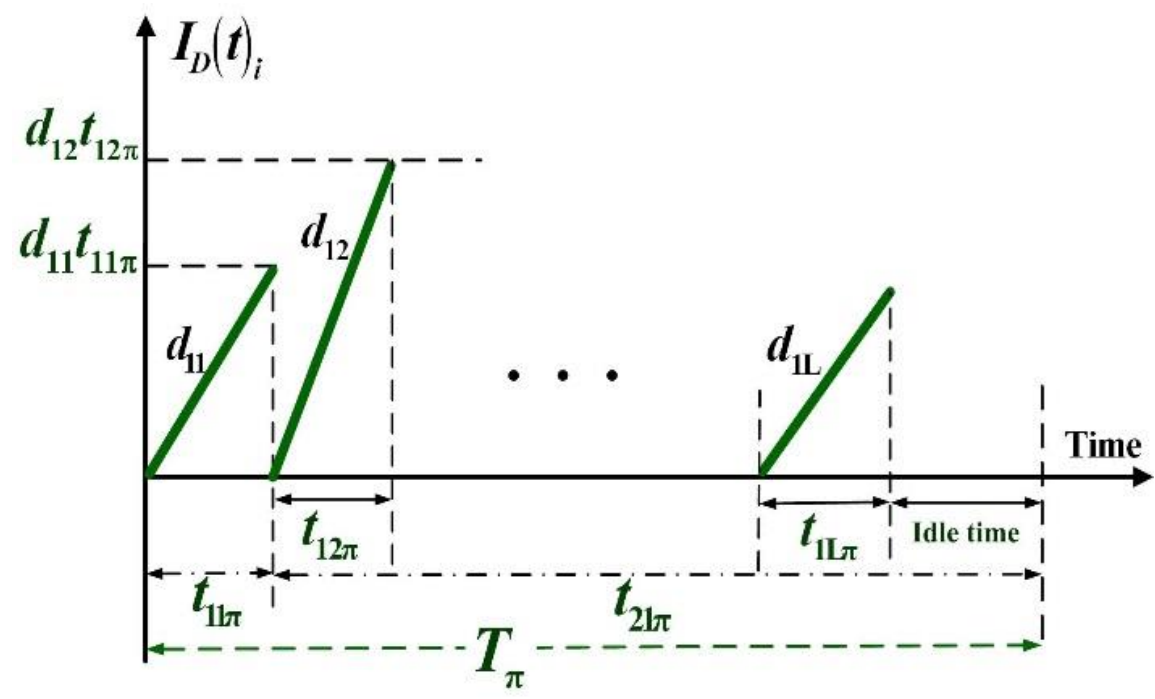

Figure 2. Inventory status of scrapped items of product $i$ in the proposed system

\section{Formulation and Optimization Approach}

\subsection{Prerequisite Condition on Capacity}

Based on the assumptions, to ensure that the production units have adequate capacity to fabricate $L$ different products, the following prerequisite equation must hold (Nahmias, 2009):

$$
\sum_{i=1}^{L}\left(\frac{\left(1-\pi_{i}\right) \lambda_{i}}{\left[1-E\left[x_{i}\right]\left(1-\pi_{i}\right)\right]} \cdot \frac{1}{P_{1 i}}\right)<1
$$

From the description of the proposed system with an external source and random scrap, and by examination of Figures 1 to 4 , the following formulas can be gained (for $i=1,2, \ldots, L$ ):

$$
\begin{aligned}
& H_{1 i}=\left(P_{1 i}-d_{1 i}\right) t_{1 i \pi} \\
& t_{1 i \pi}=\frac{\left(1-\pi_{i}\right) Q_{i}}{P_{1 i}}=\frac{H_{1 i}}{P_{1 i}-d_{1 i}} \\
& H_{i}=H_{1 i}+\pi_{i} Q_{i}=\lambda_{i} \cdot T_{\pi}
\end{aligned}
$$




$$
\begin{aligned}
& T_{\pi}=t_{1 i \pi}+t_{2 i \pi} \\
& t_{2 i \pi}=T_{\pi}-t_{1 i \pi}=n \cdot t_{n i \pi} \\
& d_{1 i} t_{1 i \pi}=x_{i} P_{1 i} t_{1 i \pi}=x_{i}\left[\left(1-\pi_{i}\right) Q_{i}\right] \\
& Q_{i}=\frac{\lambda_{i} T_{\pi}}{\left[1-x_{i}\left(1-\pi_{i}\right)\right]}
\end{aligned}
$$

In the shipping time $t_{2 i \pi}$ of end item $i$, total inventories are (Chiu et al., 2009):

$$
\left(\frac{1}{n^{2}}\right)\left(\sum_{i=1}^{n-1} i\right) H_{i} t_{2 i \pi}=\left(\frac{1}{n^{2}}\right)\left[\frac{n(n-1)}{2}\right] H_{i} t_{2 i \pi}=\left(\frac{n-1}{2 n}\right) H_{i} t_{2 i \pi}
$$

In the sales units, since $n$ installments of fixed-amount of $H_{i}$ are shipped to sales units at fixed time $t_{\mathrm{ni}}$, the following formulas could be gained according to the assumption of the system:

$$
\begin{aligned}
& D_{i}=\frac{H_{i}}{n} \\
& t_{n i \pi}=\frac{t_{2 i \pi}}{n} \\
& I_{i}=D_{i}-\lambda_{i} t_{n i \pi} .
\end{aligned}
$$

Total inventories of product $i$ in the sales units are (Chiu et al., 2009):

$$
\frac{1}{2}\left[\frac{H_{i} t_{2 i \pi}}{n}+T_{\pi}\left(H_{i}-\lambda_{i} t_{2 i \pi}\right)\right]
$$

Total cost per cycle, $\operatorname{TC}\left(T_{\pi}, n\right)$ for $L$ products include fixed and variable costs for outsourced items, setup and variable costs in the production units, disposal cost for scrapped items, fixed and variable costs for shipping end products to sales units, holding costs for finished and scrapped items in $T_{\pi}$ and holding cost for end products in the sales units, as shown in Eq. (14).

$$
\begin{aligned}
& T C\left(T_{\pi}, n\right)= \\
& \sum_{i=1}^{L}\left\{\begin{array}{c}
K_{\pi i}+C_{\pi i}\left(\pi_{i} Q_{i}\right)+K_{i}+C_{i}\left(1-\pi_{i}\right) Q_{i}+C_{S i} x_{i}\left[\left(1-\pi_{i}\right) Q_{i}\right]+n K_{1 i} \\
+C_{T} Q_{i}\left[1-x_{i}\left(1-\pi_{i}\right)\right]+h_{i}\left[\frac{H_{1 i}+d_{1 i} t_{1 i \pi}}{2}\left(t_{1 i \pi}\right)+\left(\frac{n-1}{2 n}\right) H_{i}\left(t_{2 i \pi}\right)\right] \\
+\frac{h_{2 i}}{2}\left[\frac{H_{i} t_{2 i \pi}}{n}+T_{\pi}\left(H_{i}-\lambda_{i} t_{2 i \pi}\right)\right]
\end{array}\right\} .
\end{aligned}
$$

Using $E\left[x_{i}\right]$ to deal with randomness of $x_{i}$, substituting the relating factors $\beta_{1 i}$ and $\beta_{2 i}$, also substituting Eqs. (2) to (13) in Eq. (14), with additional derivations, the expected annual system costs $\mathrm{E}\left[T C U\left(T_{\pi}, n\right)\right]$ can be gained as follows: 


$$
\begin{aligned}
& E\left[\operatorname{TCU}\left(T_{\pi}, n\right)\right]=\frac{E\left[T C\left(T_{\pi}, n\right)\right]}{E\left[T_{\pi}\right]} \\
& =\sum_{i=1}^{L}\left\{\frac{K_{i}\left(1+\beta_{1 i}\right)}{T_{\pi}}+\frac{K_{i}}{T_{\pi}}+\frac{n K_{1 i}}{T_{\pi}}+C_{T i} \lambda_{i}\right\} \\
& +\sum_{i=1}^{L} E_{0 i}\left\{\begin{array}{c}
\left(1+\beta_{2 i}\right) C_{i} \pi_{i}+C_{i}\left(1-\pi_{i}\right)+C_{S i} E\left[x_{i}\right]\left(1-\pi_{i}\right)+\frac{h_{2 i} T_{\pi} E_{4 i}}{2} \\
+\frac{h_{i} T_{\pi}}{2 E_{1 i}}\left[E_{1 i}{ }^{2}+E_{4 i}\left[E\left[x_{i}\right]\left(1-\pi_{i}\right)-\pi_{i}\right]\right]+\frac{T_{\pi}\left(h_{2 i}-h_{i}\right)}{2}\left(\frac{1}{n}\right)\left(E_{1 i}-E_{4 i}\right)
\end{array}\right\}
\end{aligned}
$$

where, $E_{0 i}=\frac{\lambda_{i}}{\left[1-E\left[x_{i}\right]\left(1-\pi_{i}\right)\right]} ; E_{1 i}=\left[1-E\left[x_{i}\right]\left(1-\pi_{i}\right)\right] ; E_{4 i}=\left[\frac{\lambda_{i}\left(1-\pi_{i}\right)}{P_{1 i}}\right]$.

\subsection{Convexity of the Expected Annual System Costs}

The convexity of $\mathrm{E}\left[\operatorname{TCU}\left(T_{\pi}, n\right)\right]$ is demonstrated by using the Hessian matrix equations (refer to Rardin, 1998). The following are results of partial derivatives:

$$
\begin{aligned}
& \frac{\partial^{2} E\left[\operatorname{TCU}\left(T_{\pi}, n\right)\right]}{\partial T_{\pi}{ }^{2}}=\sum_{i=1}^{L} 2\left[\frac{K_{i}\left(1+\beta_{1 i}\right)+\left(K_{i}+n K_{1 i}\right)}{T_{\pi}{ }^{3}}\right] \\
& \frac{\partial^{2} E\left[T C U\left(T_{\pi}, n\right)\right]}{\partial n^{2}}=\sum_{i=1}^{L} E_{0 i}\left[T_{\pi}\left(h_{2 i}-h_{i}\right)\left(\frac{1}{n^{3}}\right)\left(E_{1 i}-E_{4 i}\right)\right] \\
& \frac{\partial E\left[T C U\left(T_{\pi}, n\right)\right]}{\partial T_{\pi} \partial n}=\sum_{i=1}^{L}\left[\frac{-K_{1 i}}{T_{\pi}{ }^{2}}\right]+\sum_{i=1}^{L} \lambda_{i}\left[\frac{-\left(h_{2 i}-h_{i}\right)}{2}\left(\frac{1}{n^{2}}\right)\left(E_{1 i}-E_{4 i}\right)\right] .
\end{aligned}
$$

Substitute Eqs. (16) to (18) in the Hessian matrix equations, and with extra derivations, Eq. (19) could be obtained:

$$
\left[\begin{array}{ll}
T_{\pi} & n
\end{array}\right] \cdot\left(\begin{array}{ll}
\frac{\partial^{2} E\left[T C U\left(T_{\pi}, n\right)\right]}{\partial T_{\pi}^{2}} & \frac{\partial^{2} E\left[T C U\left(T_{\pi}, n\right)\right]}{\partial T_{\pi} \partial n} \\
\frac{\partial^{2} E\left[T C U\left(T_{\pi}, n\right)\right]}{\partial T_{\pi} \partial n} & \frac{\partial^{2} E\left[T C U\left(T_{\pi}, n\right)\right]}{\partial n^{2}}
\end{array}\right) \cdot\left[\begin{array}{c}
T_{\pi} \\
n
\end{array}\right]=2 \sum_{i=1}^{L}\left[\frac{K_{i}\left(1+\beta_{1 i}\right)+K_{i}}{T_{\pi}}\right]>0 .
$$

For $T_{\pi},\left(1+\beta_{1 i}\right)$, and $K_{i}$ are all great than zero, thus Eq. (19) $>0$. We confirm that $\mathrm{E}\left[\operatorname{TCU}\left(T_{\pi}, n\right)\right]$ is strictly convex for all $n$ and $T_{\pi}$ other than zero, and the minimum expected system costs exist.

\subsection{Optimal Cycle Time and Shipment Decision}

To simultaneously locate optimal $T_{\pi}^{*}$ and $n^{*}$, we set the first-derivatives of $\operatorname{E}\left[\operatorname{TCU}\left(T_{\pi}, n\right)\right]$ concerning $n$ and $T_{\pi}$ equal to zero, then, solve the linear system:

$$
\frac{\partial E\left[\operatorname{TCU}\left(T_{\pi}, n\right)\right]}{\partial n}=\sum_{i=1}^{L}\left[\frac{K_{1 i}}{T_{\pi}}\right]-\sum_{i=1}^{L} E_{0 i}\left[\frac{T_{\pi}\left(h_{2 i}-h_{i}\right)}{2}\left(\frac{1}{n^{2}}\right)\left(E_{1 i}-E_{4 i}\right)\right]=0
$$


International Journal of Mathematical, Engineering and Management Sciences

Vol. 5, No. 4, 614-630, 2020

https://doi.org/10.33889/IJMEMS.2020.5.4.050

$$
\begin{aligned}
\frac{\partial E\left[\operatorname{TCU}\left(T_{\pi}, n\right)\right]}{\partial T_{\pi}} & \\
& =\sum_{i=1}^{L}\left\{\frac{-K_{i}\left(1+\beta_{1 i}\right)}{T_{\pi}^{2}}-\frac{K_{i}}{T_{\pi}^{2}}-\frac{n K_{1 i}}{T_{\pi}^{2}}\right\} \\
& +\sum_{i=1}^{L} E_{0 i}\left\{\frac{h_{2 i} E_{4 i}}{2}+\frac{h_{i}}{2 E_{1 i}}\left[E_{1 i}^{2}+E_{4 i}\left[E\left[x_{i}\right]\left(1-\pi_{i}\right)-\pi_{i}\right]\right]\right. \\
& \left.+\frac{\left(h_{2 i}-h_{i}\right)}{2}\left(\frac{1}{n}\right)\left(E_{1 i}-E_{4 i}\right)\right\}=0 .
\end{aligned}
$$

With additional derivations, the following optimal $T_{\pi}^{*}$ and $n^{*}$ are located:

$$
T_{\pi}^{*}=\sqrt{\frac{2 \sum_{i=1}^{L}\left[K_{i}\left(2+\beta_{1 i}\right)+n K_{i}\right]}{\sum_{i=1}^{L}\left\{E_{0 i}\left[\frac{h_{i}}{E_{1 i}}\left[E_{1 i}^{2}+E_{4 i}\left[E\left[x_{i}\right]\left(1-\pi_{i}\right)-\pi_{i}\right]\right]+h_{2 i} E_{4 i}+\left(h_{2 i}-h_{i}\right)\left(\frac{1}{n}\right)\left(E_{1 i}-E_{4 i}\right)\right]\right\}}}
$$

and

$$
n^{*}=\sqrt{\frac{\sum_{i=1}^{L}\left[K_{i}\left(2+\beta_{1 i}\right)\right] \cdot \sum_{i=1}^{L}\left[E_{0 i}\left(h_{2 i}-h_{i}\right)\left(E_{1 i}-E_{4 i}\right)\right]}{\sum_{i=1}^{L}\left(K_{1 i}\right) \cdot \sum_{i=1}^{L}\left\{E_{0 i}\left[h_{2 i} E_{4 i}+\frac{h_{i}}{E_{1 i}}\left[E_{1 i}^{2}+E_{4 i}\left[E\left[x_{i}\right]\left(1-\pi_{i}\right)-\pi_{i}\right]\right]\right\}\right\}}}
$$

where,

$$
E_{0 i}=\frac{\lambda}{\left[1-E\left[x_{i}\right]\left(1-\pi_{i}\right)\right]} ; E_{1 i}=\left[1-E\left[x_{i}\right]\left(1-\pi_{i}\right)\right] ; E_{4 i}=\left[\frac{\lambda\left(1-\pi_{i}\right)}{P_{1 i}}\right]
$$

\subsection{The Potential Impact from the Setup Times}

The following condition must be true to ensure rotation cycle time $T_{\pi}$ is sufficiently large to accommodate the summation of setup times of $L$ distinct products:

$$
T_{\pi}>\sum_{i=1}^{L}\left[S_{i}+\left(\frac{\left(1-\pi_{i}\right) Q_{i}}{P_{1 i}}\right)\right]
$$

Substitute $Q_{i}=\frac{\lambda_{i} T_{\pi}}{\left[1-E\left[x_{i}\right]\left(1-\pi_{i}\right)\right]}$ in Eq. (25), we obtain:

$$
T_{\pi}>\sum_{i=1}^{L}\left(S_{i}\right)+\sum_{i=1}^{L}\left[\frac{\left(1-\pi_{i}\right) \lambda_{i} T}{P_{1 i}\left[1-E\left[x_{i}\right]\left(1-\pi_{i}\right)\right]}\right]
$$

or

$$
T_{\pi}>\frac{\sum_{i=1}^{L}\left(S_{i}\right)}{1-\sum_{i=1}^{L}\left[\frac{\left(1-\pi_{i}\right) \lambda_{i}}{P_{1 i}\left[1-E\left[x_{i}\right]\left(1-\pi_{i}\right)\right]}\right]}=T_{\min }
$$


International Journal of Mathematical, Engineering and Management Sciences

Vol. 5, No. 4, 614-630, 2020

https://doi.org/10.33889/IJMEMS.2020.5.4.050

That is, as the sum of multiproduct setup times grows and becomes a significant factor as compare to $T_{\pi}$, the decision-makers must pick the maximum of $T_{\pi} *$ (Eq. (22)) or $T_{\min }$ (Eq. (27)) as stated by Nahmias (2009).

\section{Numerical Example with Discussion}

A numerical example is provided in this section to express the applicability of our research results. Five different products are to be fabricated by production units of the proposed multiproduct intrasupply chain system and each product's related parameter values displayed in Table 1.

Table 1. Values of system parameters used in the section of numerical example

\begin{tabular}{cccccccccccccccc}
\hline $\begin{array}{c}\text { Product } \\
\text { number }\end{array}$ & $\lambda_{i}$ & $P_{1 i}$ & $x_{i}$ & $C_{\mathrm{S} i}$ & $C_{i}$ & $\pi_{i}$ & $\beta_{2 i}$ & $C_{\pi i}$ & $K_{i}$ & $\beta_{1 i}$ & $K_{\pi i}$ & $h_{i}$ & $K_{1 i}$ & $C_{\mathrm{T} i}$ & $h_{2 i}$ \\
\hline 1 & 3000 & 58000 & $5 \%$ & 20 & 80 & 0.4 & 0.40 & 112.0 & 10000 & -0.60 & 4000 & 10 & 2300 & 0.1 & 50 \\
2 & 3200 & 59000 & $10 \%$ & 25 & 90 & 0.4 & 0.35 & 121.5 & 11000 & -0.65 & 3850 & 15 & 2400 & 0.2 & 55 \\
3 & 3400 & 60000 & $15 \%$ & 30 & 100 & 0.4 & 0.30 & 130.0 & 12000 & -0.70 & 3600 & 20 & 2500 & 0.3 & 60 \\
4 & 3600 & 61000 & $20 \%$ & 35 & 110 & 0.4 & 0.25 & 137.5 & 13000 & -0.75 & 3250 & 25 & 2600 & 0.4 & 65 \\
5 & 3800 & 62000 & $25 \%$ & 40 & 120 & 0.4 & 0.20 & 144.0 & 14000 & -0.80 & 2800 & 30 & 2700 & 0.5 & 70 \\
\hline
\end{tabular}

By applying equations (22), (23), and (15), at average outsourcing factor $(\bar{\pi})$ is 0.4 , we obtain the optimal $n^{*}$ is 3; the optimal common fabrication cycle time, $T_{\pi}^{*}$ is 0.6186 ; and $\mathrm{E}\left[\operatorname{TCU}\left(T_{\pi}^{*}, n^{*}\right)\right]$ is $\$ 2,421,363$. Figure 3 illustrates the joint impacts of variations in $n$ and $T_{\pi}$ on $\operatorname{E}\left[\operatorname{TCU}\left(T_{\pi}^{*}, n^{*}\right)\right]$. Additionally, the effects of differences in main system factors on the proposed multiproduct intrasupply chain system are explored as follows:

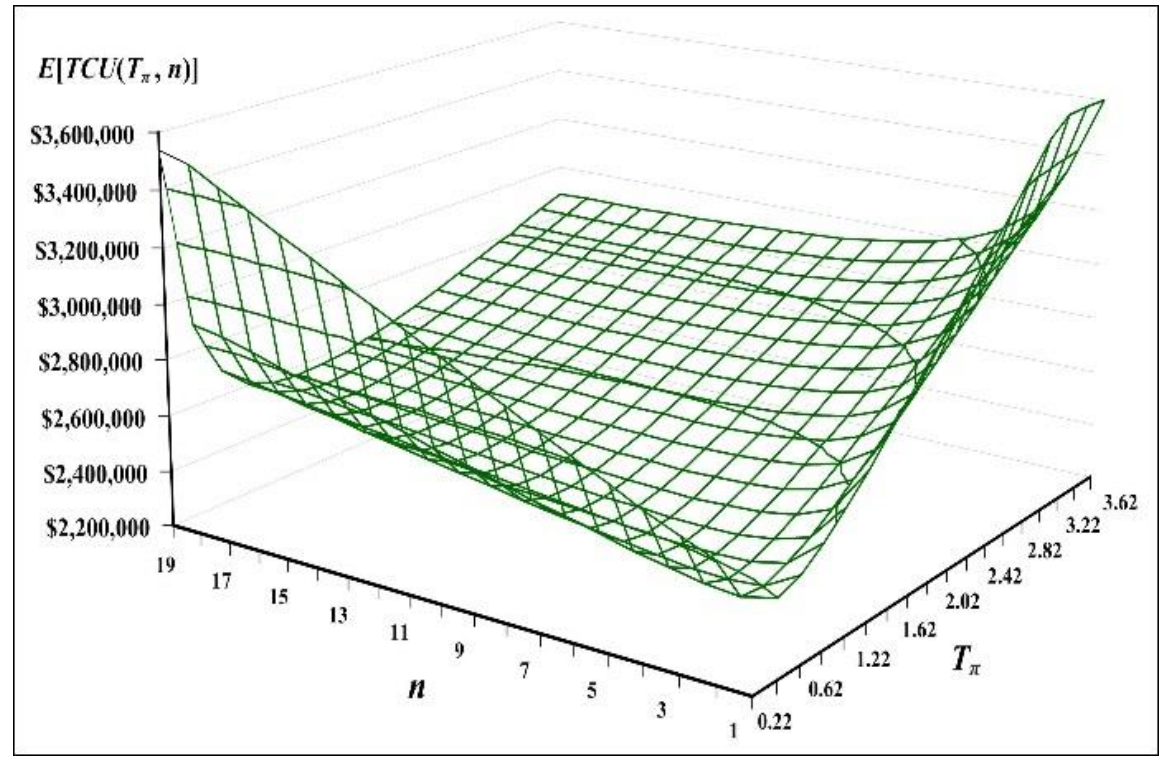

Figure 3. Joint impacts of variations in $n$ and $T_{\pi}$ on $\mathrm{E}\left[\operatorname{TCU}\left(T_{\pi}^{*}, n^{*}\right)\right]$ 
International Journal of Mathematical, Engineering and Management Sciences

Vol. 5, No. 4, 614-630, 2020

https://doi.org/10.33889/IJMEMS.2020.5.4.050

\subsection{The Effect of Variations in the Average Outsourcing Factor}

With help from the proposed model, variations in the average outsourcing factor effect on various system parameters can now be analyzed and the results are revealed in Table 2.

Table 2. Effects of changes in the average outsourcing factor on various system parameters

\begin{tabular}{|c|c|c|c|c|c|c|c|c|c|c|c|}
\hline $\bar{\pi}$ & $n^{*}$ & $T_{\pi}^{*}$ & $\begin{array}{l}\text { Outsourcing } \\
\text { related cost } \\
\text { (A) }\end{array}$ & $\begin{array}{c}\% \\
(\mathrm{~A}) /(\mathrm{C})\end{array}$ & $\begin{array}{l}\text { In-house cost } \\
\text { (B) }\end{array}$ & $\begin{array}{c}\% \\
(\mathrm{~B}) /(\mathrm{C})\end{array}$ & $\begin{array}{c}\mathrm{E}\left[\operatorname{TCU}\left(T_{\pi}^{*}, n^{*}\right)\right] \\
(\mathrm{C}) \\
=(\mathrm{A})+(\mathrm{B})\end{array}$ & $\begin{array}{c}\% \\
\text { change }\end{array}$ & $\begin{array}{l}\text { Machine } \\
\text { utilization }\end{array}$ & $\begin{array}{l}\text { Quality cost } \\
\text { (D) }\end{array}$ & $\begin{array}{l}\% \\
\text { (D)/ } \\
\text { (C) }\end{array}$ \\
\hline 0.00 & 3 & 0.6045 & $\$ 0$ & $0 \%$ & $\$ 2,284,592$ & $100 \%$ & $\$ 2,284,592$ & - & $30.70 \%$ & $\$ 209,158$ & $9.16 \%$ \\
\hline 0.05 & 3 & 6065 & $\$ 148,663$ & $6.39 \%$ & & $93.61 \%$ & $\$ 2,327,153$ & & & & $8.16 \%$ \\
\hline 0.10 & 3 & 0.6084 & $\$ 267$ & $11.42 \%$ & 073,426 & $88.58 \%$ & $\$ 2,340,725$ & $2.46 \%$ & & $\$ 171,875$ & $7.34 \%$ \\
\hline 0.15 & 3 & 0.6103 & $\$ 384,877$ & $16.35 \%$ & 969,383 & $83.65 \%$ & $\$ 2,354,260$ & $3.05 \%$ & & & $6.57 \%$ \\
\hline 0.20 & 3 & 0.6121 & $\$ 501,4$ & $21.18 \%$ & & $78.82 \%$ & $\$ 2,3$ & $3.64 \%$ & & & $5.85 \%$ \\
\hline 0.25 & 3 & 0.6138 & $\$ 616,924$ & $25.91 \%$ & & $74.09 \%$ & $\$ 2,38$ & $4.23 \%$ & & & $5.18 \%$ \\
\hline 0.30 & 3 & 0.6155 & $\$ 731,426$ & $30.54 \%$ & & $69.46 \%$ & $\$ 2,394,637$ & 4.82 & & 9,103 & $4.56 \%$ \\
\hline 0.35 & 3 & 0.6171 & $\$ 844,934$ & $35.09 \%$ & & $64.91 \%$ & $\$ 2,408$, & & & & $3.98 \%$ \\
\hline 0.40 & 3 & 0.6186 & $\$ 957,464$ & $39.54 \%$ & 899 & $60.46 \%$ & $\$ 2,421,363$ & $5.99 \%$ & & & $3.44 \%$ \\
\hline 0.45 & 3 & 6200 & $\$ 1,069,032$ & $43.91 \%$ & & 56.09 & & & & & $2.95 \%$ \\
\hline 0.50 & 3 & 0.6214 & $\$ 1,179,651$ & $48.19 \%$ & & $51.81 \%$ & $\$ 2,447$, & & & & $2.50 \%$ \\
\hline 0.55 & 3 & 0.6227 & $\$ 1,289,3$ & $52.39 \%$ & & $47.61 \%$ & & & & & $2.09 \%$ \\
\hline 0.60 & 3 & 0.6239 & $\$ 1,398,102$ & $56.50 \%$ & $\$ 1,076,254$ & $43.50 \%$ & $\$ 2,474,357$ & & & & $1.72 \%$ \\
\hline 0.635 & 3 & 0.6248 & $\$ 1,473,699$ & $59.34 \%$ & & $40.66 \%$ & $\$ 2,483,567$ & & & $\$ 36,697$ & $1.48 \%$ \\
\hline 0.65 & 3 & 0.6251 & $\$ 1,505,962$ & $60.54 \%$ & 1,547 & $39.46 \%$ & $\$ 2,487,509$ & & 10. & 56 & $1.38 \%$ \\
\hline 0.70 & 3 & 0.6262 & $\$ 1,612,930$ & $64.50 \%$ & $\$ 887,693$ & $35.50 \%$ & $\$ 2,500,622$ & $9.46 \%$ & $8.69 \%$ & $\$ 27,084$ & $1.08 \%$ \\
\hline 0.75 & 3 & 0.6273 & $\$ 1,719,018$ & $68.39 \%$ & & $31.61 \%$ & $\$ 2,513,697$ & $10.03 \%$ & & & $0.82 \%$ \\
\hline 0.80 & 3 & 0.6282 & $\$ 1,824,239$ & $72.20 \%$ & $\$ 702,494$ & $27.80 \%$ & $\$ 2,526,733$ & $10.60 \%$ & $5.75 \%$ & $\$ 14,955$ & $0.59 \%$ \\
\hline 0.85 & 3 & 0.6292 & & $75.94 \%$ & & $24.06 \%$ & $\$ 2,539,730$ & & & & $0.40 \%$ \\
\hline 0.90 & 3 & 0.6300 & $\$ 2,032,134$ & $79.61 \%$ & $\$ 520,555$ & $20.39 \%$ & $\$ 2,552,689$ & $11.73 \%$ & & $\$ 5,960$ & $0.23 \%$ \\
\hline 0.95 & 3 & 0.6308 & $\$ 2,134,831$ & $83.21 \%$ & $\$ 430,778$ & $16.79 \%$ & $\$ 2,565,608$ & $12.30 \%$ & $1.42 \%$ & $\$ 2,607$ & $0.10 \%$ \\
\hline 1.00 & 3 & 0.6315 & $\$ 2,236,710$ & $90.06 \%$ & $\$ 246,773$ & $9.94 \%$ & $\$ 2,483,483$ & $8.71 \%$ & $0 \%$ & $\$ 0$ & $0.00 \%$ \\
\hline
\end{tabular}

For each product, further investigation on differences in the average outsourcing factor effect on their total cost is conducted and the results are shown in Figure 4. It can be seen that due to unit outsourcing cost is higher than unit in-house fabrication cost, the total cost for each of the five-item raises, as the average outsourcing factor increases.

Conversely, Figure 5 exhibits the benefit gained from implementing outsourcing policy. Unsurprisingly, it shows that each item's machine utilization declines as the average outsourcing factor increases. From Table 2, it is also noted that without implementing the outsourcing policy, machine utilization was $30.7 \%$, and after applying a partial outsourcing plan with $\bar{\pi}=0.4$, machine utilization drops to $17.81 \%$; which is at the expense of $5.99 \%$ raise in $\mathrm{E}\left[\operatorname{TCU}\left(T_{\pi}^{*}, n^{*}\right)\right]$ (for $\mathrm{E}\left[\operatorname{TCU}\left(T_{\pi}^{*}, n^{*}\right)\right]$ rises to $\$ 2,421,363$ from $\left.\$ 2,284,592\right)$. 
International Journal of Mathematical, Engineering and Management Sciences

Vol. 5, No. 4, 614-630, 2020

https://doi.org/10.33889/IJMEMS.2020.5.4.050

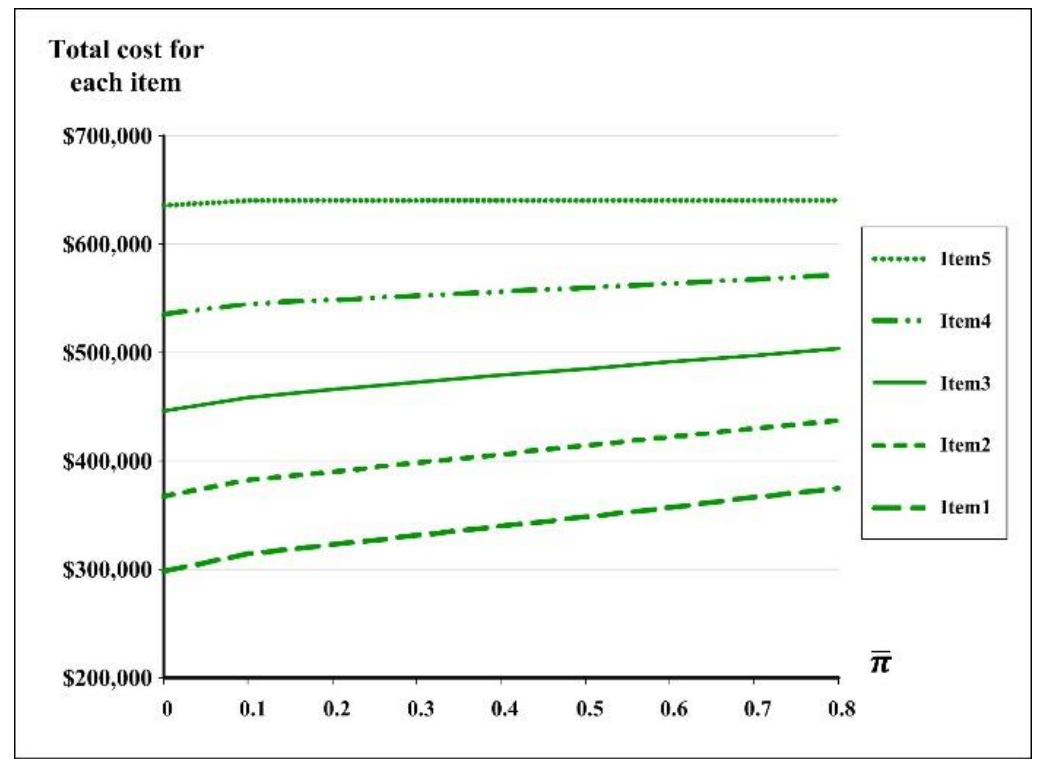

Figure 4. Impact of changes in $\bar{\pi}$ on each product's total cost

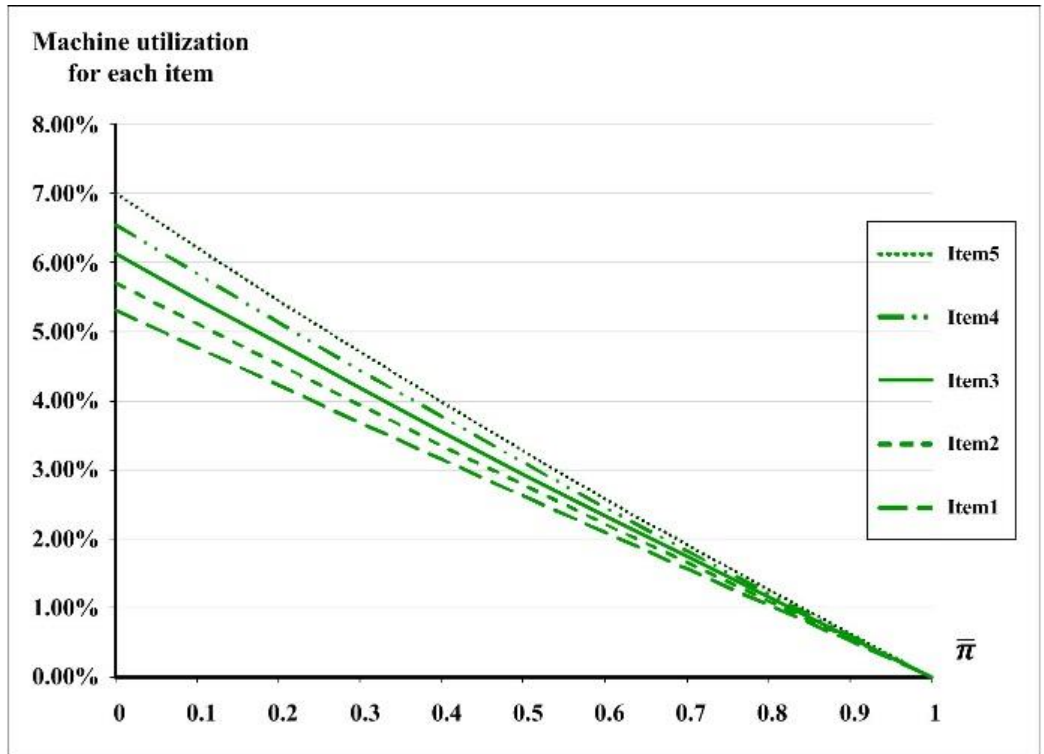

Figure 5. Impact of variations in $\bar{\pi}$ on machine utilization for each product

A critical ratio of $\bar{\pi}$, which can support the make-or-buy decision making, is also obtainable from our proposed model. With extra analyses, we reveal an important fact, that is, as $\bar{\pi}$ goes up to and higher than 0.635, for the cost savings reason, the management should decide to implement a 100\% outsourcing policy (i.e., a 'buy' decision) for these five products (see Table 2 and Figure 6). 
International Journal of Mathematical, Engineering and Management Sciences

Vol. 5, No. 4, 614-630, 2020

https://doi.org/10.33889/IJMEMS.2020.5.4.050

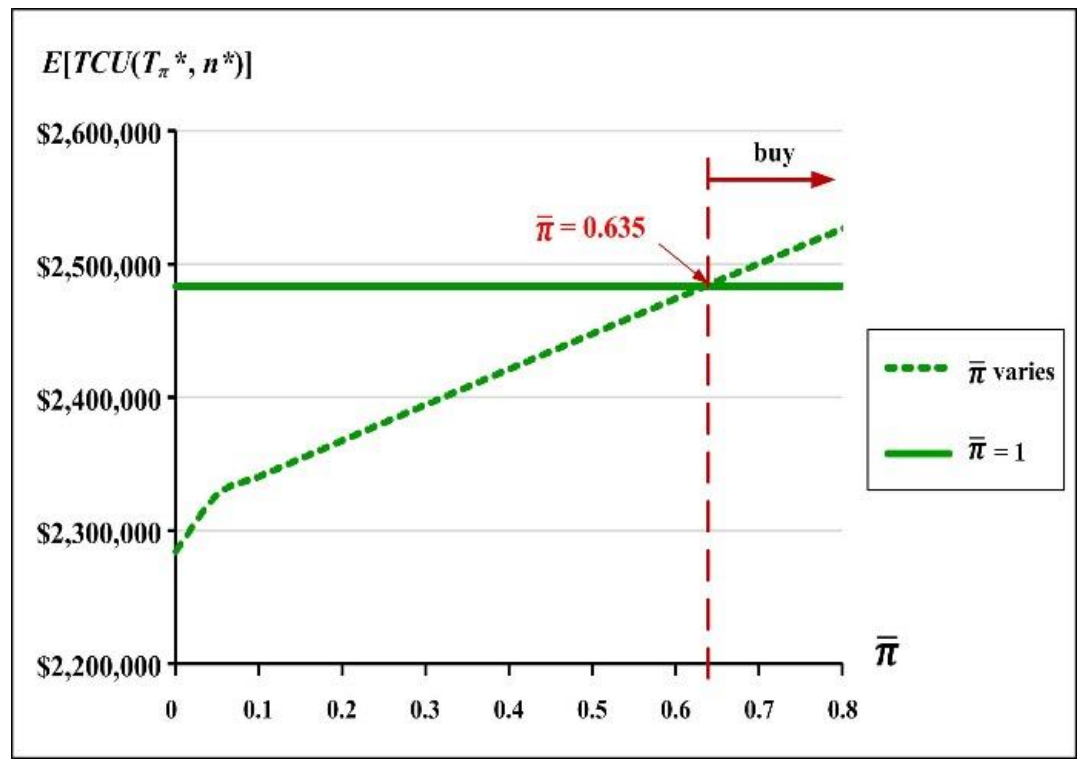

Figure 6. Effect of differences in $\bar{\pi}$ on management's make-or-buy decision making

\subsection{The Impact of the Difference in the Average Fabrication Scrap Rate Factor}

Due to random scrap, the quality cost is $\$ 83,343$ or $3.44 \%$ of $\mathrm{E}\left[T C U\left(T_{\pi}^{*}, n^{*}\right)\right]$ (see Table 2), and the impact of variations in the average in-house fabrication scrap rate on system's cost components is examined and its outcome is depicted in Figure 7. It particularly indicates that the system's quality cost increases significantly, as $\bar{x}$ goes up.

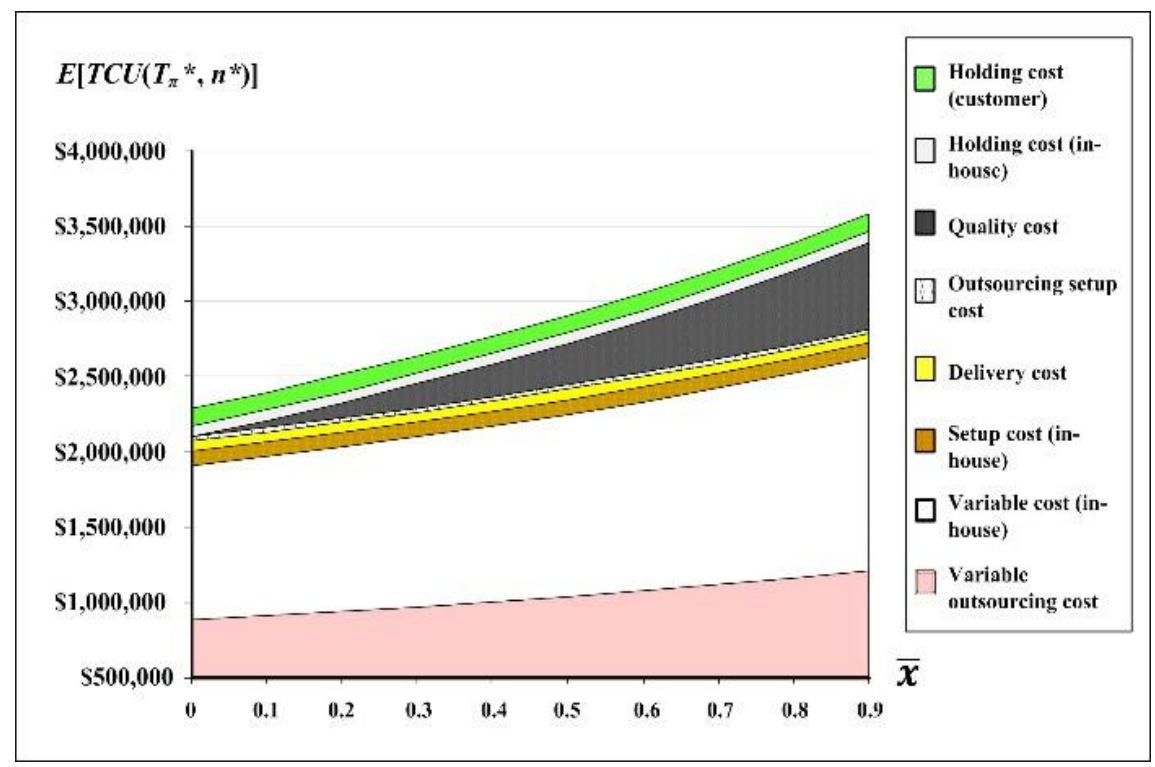

Figure 7. Impact of variations in $\bar{x}$ on system's cost components 
Figure 8 illustrates additional analytical results regarding the effect of differences in $\bar{x}$ on makeor-buy decision making. It indicates that for $\bar{\pi}=0.4$ (as assumed in our example), if the in-house fabrication system's average scrap rate $\bar{x}$ increases to $24.2 \%$ and up, for the cost-savings reason the management should consider to put in practice a $100 \%$ outsourcing policy (i.e., buy) for these five products. The extra analysis also reveals that for $\bar{\pi}=0$ the critical $\bar{x}$ ratio raises to $30.7 \%$, which means that if a fabrication system has an average scrap rate $\bar{x}$ over $30.7 \%$, management should completely rule out any hybrid type of in-house fabrication plan.

\subsection{Effects of Variations in Other Parameters on E[TCU( $\left.\left.\mathbf{T}_{\pi}^{*}, \mathbf{n}^{*}\right)\right]$ and $\mathbf{T}_{\pi}{ }^{*}$}

The impact of variations in the average outsourcing unit cost factor $\overline{\beta_{2}}$ on the expected annual system costs $\mathrm{E}\left[\operatorname{TCU}\left(T_{\pi}^{*}, n^{*}\right)\right]$ is further investigated and the result is exhibited in Figure 9. Predictably, $\mathrm{E}\left[\operatorname{TCU}\left(T_{\pi}^{*}, n^{*}\right)\right]$ increases notably, as the average outsourcing unit cost factor $\overline{\beta_{2}}$ moves up.

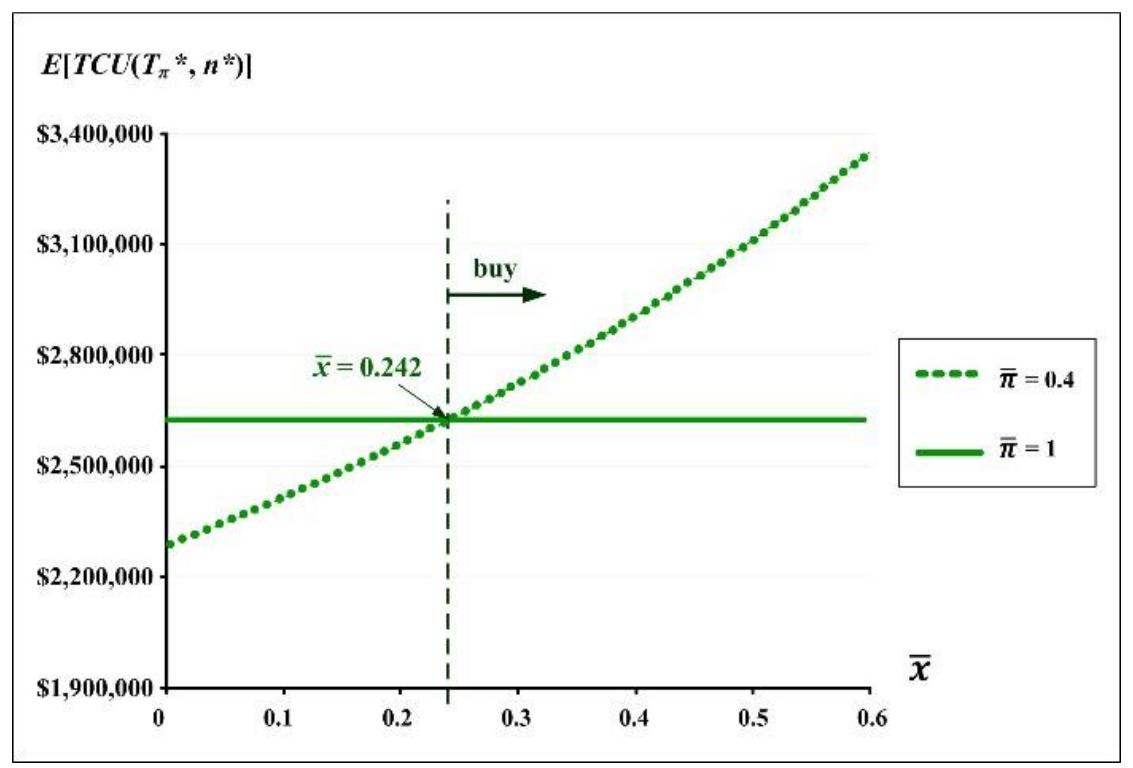

Figure 8. Effect of differences in $\bar{x}$ on management's make-or-buy decision making

Figure 10 displays the joint effects of differences in the fabrication cycle time $T_{\pi}$ and the average outsourcing factor $\bar{\pi}$ on $\mathrm{E}\left[\operatorname{TCU}\left(T_{\pi}, n\right)\right]$. It points out that as $\bar{\pi}$ raises, the expected annual system costs $\mathrm{E}\left[\operatorname{TCU}\left(T_{\pi}, n\right)\right]$ increases accordingly; and as $T_{\pi}$ deviates from its optimal point 0.6186 and goes up, $\mathrm{E}\left[\operatorname{TCU}\left(T_{\pi}, n\right)\right]$ raises drastically. 
International Journal of Mathematical, Engineering and Management Sciences

Vol. 5, No. 4, 614-630, 2020

https://doi.org/10.33889/IJMEMS.2020.5.4.050

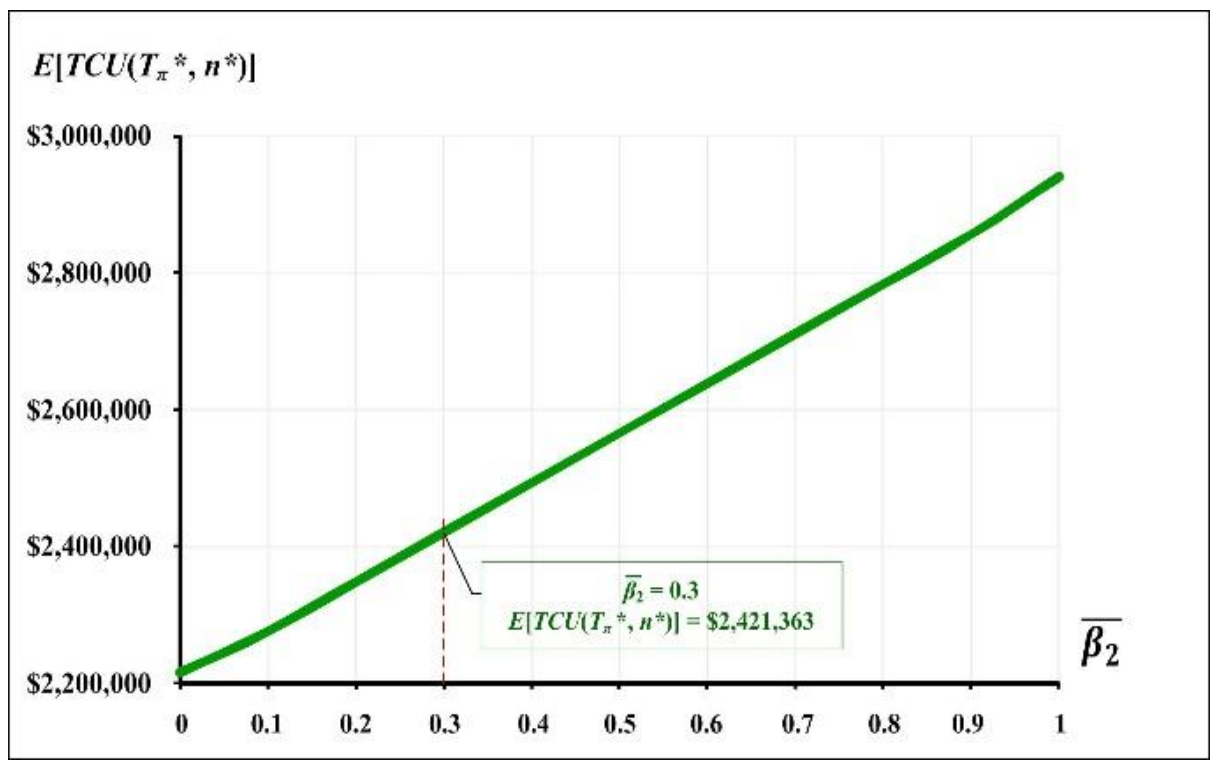

Figure 9. Impact of variations in $\overline{\beta_{2}}$ on the expected annual system costs $\operatorname{E}\left[\operatorname{TCU}\left(T_{\pi}^{*}, n^{*}\right)\right]$

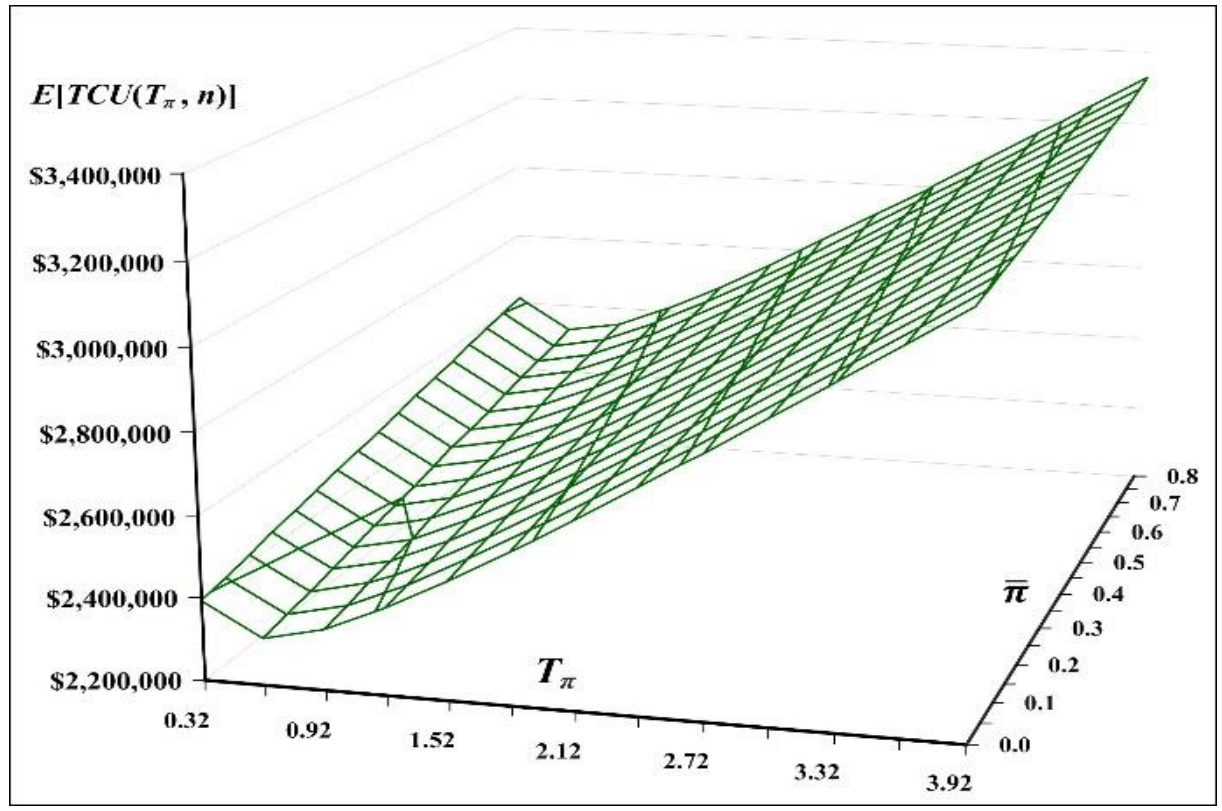

Figure 10. The joint impact of differences in $T_{\pi}$ and $\bar{\pi}$ on $\mathrm{E}\left[\operatorname{TC} U\left(T_{\pi}, n\right)\right]$

Moreover, the joint influences of changes in the average fabrication scrap rate factor $\bar{x}$ and average outsourcing factor $\bar{\pi}$ on the optimal $T_{\pi}{ }^{*}$ are investigated and the result is exhibited in Figure 11. It specifies that as $\bar{x}$ goes higher, $T_{\pi}^{*}$ declines considerably, and as $\bar{\pi}$ goes up, $T_{\pi}{ }^{*}$ 
International Journal of Mathematical, Engineering and Management Sciences

Vol. 5, No. 4, 614-630, 2020

https://doi.org/10.33889/IJMEMS.2020.5.4.050

increases significantly; and in particular, when $\bar{\pi}$ decreases to near zero and $\bar{x}$ goes higher to near one, the optimal cycle time $T_{\pi}^{*}$ drops severely.

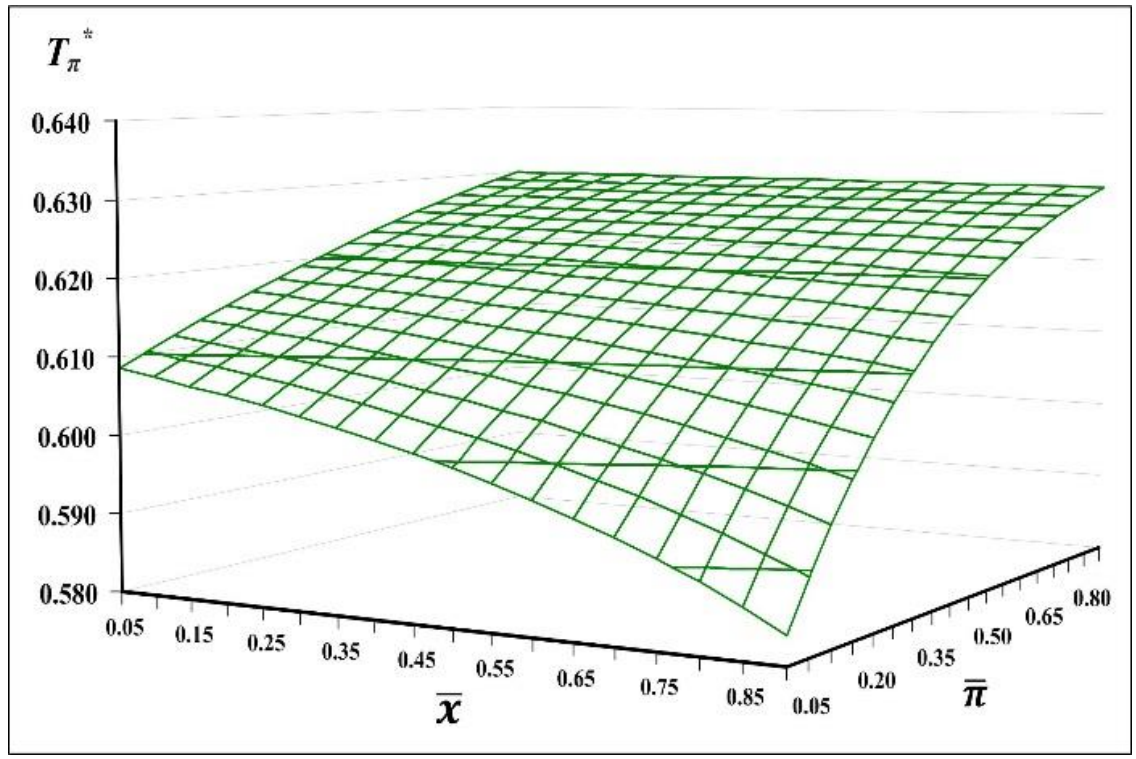

Figure 11. Joint impacts of changes in $\bar{x}$ and $\bar{\pi}$ on the optimal cycle time $T_{\pi}^{*}$

\section{Conclusions}

The fabrication cycle time and shipment decision for a multiproduct intra-supply chain system incorporating external source and random scrap are studied. We build a mathematical model to carefully portray the characteristics of the studied problem. Model analyses and a renewal reward theorem enable us to obtain the expected system cost function. The optimization techniques and Hessian matrix equations help us simultaneously decide the optimal cycle time and shipment policy that minimize the system cost. Through numerical illustration, we expose the individual and combined impact of diverse system features on the optimal operating policies and other crucial parameters of the studied problem (the details are exhibited in Section 4). These results can facilitate managerial decision makings on such a realistic intra-supply chain system. For future study, to explore the impact of stochastic demand on the same problem will be an interesting direction.

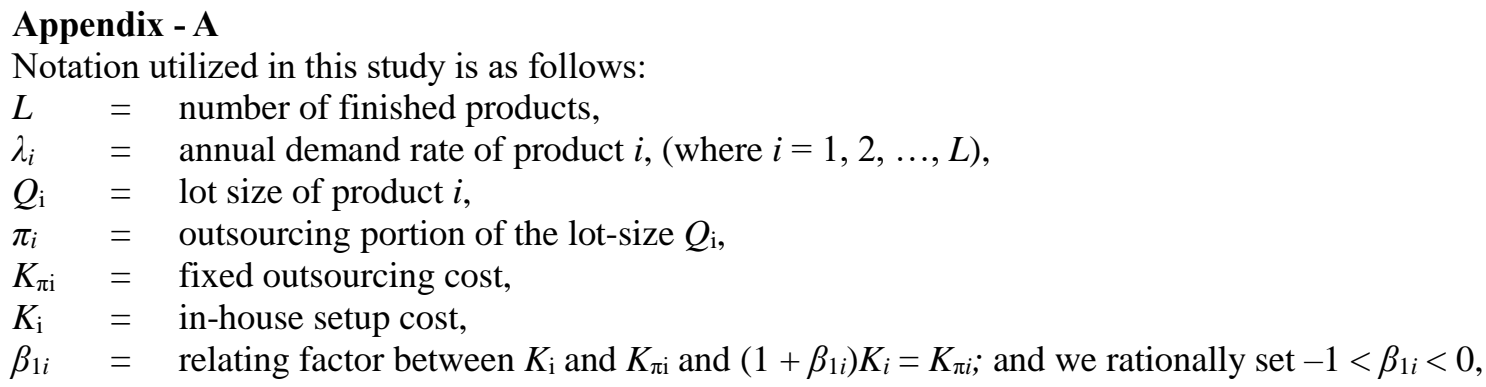


International Journal of Mathematical, Engineering and Management Sciences

Vol. 5, No. 4, 614-630, 2020

https://doi.org/10.33889/IJMEMS.2020.5.4.050

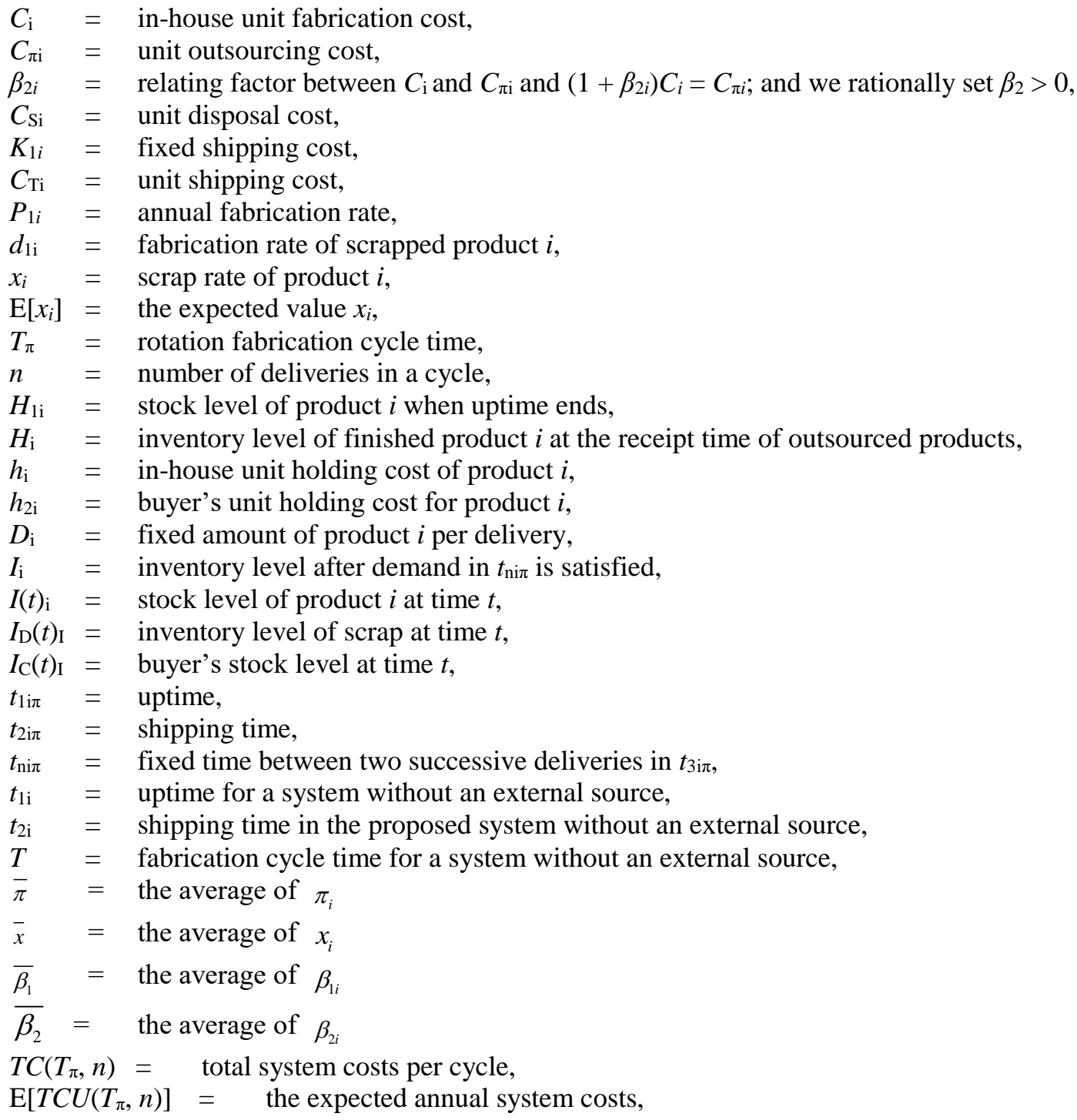

\section{Conflict of Interest}

The authors confirm that there is no conflict of interest to declare for this publication.

\section{Acknowledgments}

The authors sincerely appreciate Ministry of Science and Technology of Taiwan for supporting this research (project\#: MOST 105-2410-H-324-003).

\section{References}

Al-Bahkali, E.A., \& Abbas, A.T. (2018). Failure analysis of vise jaw holders for hacksaw machine. Journal of King Saud University-Engineering Sciences, 30(1), 68-77. 
International Journal of Mathematical, Engineering and Management Sciences

Vol. 5, No. 4, 614-630, 2020

https://doi.org/10.33889/IJMEMS.2020.5.4.050

Arya, A., Mittendorf, B., \& Sappington, D.E. (2008). The make-or-buy decision in the presence of a rival: strategic outsourcing to a common supplier. Management Science, 54(10), 1747-1758.

Ashfaq, H., Hussain, I., \& Giri, A. (2017). Comparative analysis of old, recycled and new PV modules. Journal of King Saud University-Engineering Sciences, 29(1), 22-28.

Batukhtin, A., Batukhtina, I., Bass, M., Batukhtin, S., Kobylkin, M., Baranovskaya, M., \& Baranovskaya, A. (2019). Development and experimental verification of the mathematical model of thermal inertia for a branched heat supply system. Journal of Applied Engineering Science, 17(3), 413-424.

Chiu, S.W., Lin, H.D., Cheng, C.B., \& Chung, C.L. (2009). Optimal production-shipment decisions for the finite production rate model with scrap. International Journal for Engineering Modelling, 22(1-4), 2534.

Chiu, Y.S.P., Chiu, V., Lin, H.D., \& Chang, H.H. (2019). Meeting multiproduct demand with a hybrid inventory replenishment system featuring quality reassurance. Operations Research Perspectives, 6 , 100112. Doi: 10.1016/j.orp.2019.100112.

Chiu, Y.S.P., Liu, C.J., \& Hwang, M.H. (2017). Optimal batch size considering partial outsourcing plan and rework. Jordan Journal of Mechanical and Industrial Engineering, 11(3), 195-200.

Hamers, H., Klijn, F., \& Slikker, M. (2019). Implementation of optimal schedules in outsourcing with identical suppliers. Mathematical Methods of Operations Research, 89(2), 173-187.

He, G., Wu, W., \& Zhang, Y. (2018). Analysis of a multi-component system with failure dependency, Npolicy and vacations. Operations Research Perspectives, 5, 191-198.

Henig, M., \& Gerchak, Y. (1990). The structure of periodic review policies in the presence of random yield. Operations Research, 38(4), 634-643.

Khanna, A., Kishore, A., \& Jaggi, C.K. (2017). Inventory modeling for imperfect production process with inspection errors, sales return, and imperfect rework process. International Journal of Mathematical, Engineering and Management Sciences, 2(4), 242-258.

Levina, N., \& Ross, J.W. (2003). From the vendor's perspective: exploring the value proposition in information technology outsourcing. MIS Quarterly: Management Information Systems, 27(3), 331-364.

Li, J., Blumenfeld, D.E., \& Marin, S.P. (2008). Production system design for quality robustness. IIE Transactions, 40(3), 162-176.

Lin, H.D., Chen, Y.R., Chiu, V., \& Peter, C.Y.S. (2019). A decision model for a quality-assured EPQ-based intra-supply chain system considering overtime option. Journal of Applied Engineering Science, 17(3), 362-372.

Mohammadi, M. (2017). The tradeoff between outsourcing and using more factories in a distributed flow shop system. Economic Computation and Economic Cybernetics Studies and Research, 51(4), 279-295.

Mosca, A., Vidyarthi, N., \& Satir, A. (2019). Integrated transportation-inventory models: a review. Operations Research Perspectives, 6, 100101. DOI: 10.1016/j.orp.2019.100101.

Nahmias (2009). Production and operations analysis. McGraw-Hill Inc., New York.

Rardin, R.L. (1998). Optimization in operations research. Prentice-Hall Inc., New Jersey, 739-741.

Sarker, R.A., \& Khan, L.R. (1999). An optimal batch size for a production system operating under periodic delivery policy. Computers \& Industrial Engineering, 37(4), 711-730.

Schwarz, L.B., Deuermeyer, B.L., \& Badinelli, R.D. (1985). Fill-rate optimization in a one-warehouse Nidentical retailer distribution system. Management Science, 31(4), 488-498.

Skowronski, K., \& Benton Jr, W.C. (2018). The influence of intellectual property rights on poaching in manufacturing outsourcing. Production and Operations Management, 27(3), 531-552. 
International Journal of Mathematical, Engineering and Management Sciences

Vol. 5, No. 4, 614-630, 2020

https://doi.org/10.33889/IJMEMS.2020.5.4.050

Taft, E.W. (1918). The most economical production lot. Iron Age, 101, 1410-1412.

Vujošević, M., Makajić-Nikolić, D., \& Pavlović, P. (2017). A new approach to determination of the most critical multi-state components in multi-state systems. Journal of Applied Engineering Science, 15(4), 401-405.

Zahorik, A., Thomas, L.J., \& Trigeiro, W.W. (1984). Network programming models for production scheduling in multi-stage, multi-item capacitated systems. Management Science, 30(3), 308-325.

Zhao, X., Qian, C., Nakamura, S., \& Nakagawa, T. (2018). A summary of replacement policies with number of failures. International Journal of Mathematical, Engineering and Management Sciences, 3(2), 136150 .

Zipkin, P.H. (1995). Performance analysis of a multi-item production-inventory system under alternative policies. Management Science, 41(4), 690-703. 